\title{
La libertad de expresión y el combate al discurso del odio
}

\author{
Freedom speech and combat to hate speech
}

\author{
Martín Risso FERRAND ${ }^{1}$ \\ Universidad Católica del Uruguay \\ mrisso@ucu.edu.uy
}

\begin{abstract}
Resumen: Partiendo de tres modelos de protección de la libertad de pensamiento, se realiza una aproximación a la noción de «discurso del odio», detectando las dificultades que existen para encuadrarla, los riesgos y excesos que su regulación presenta y pasando por la compleja y controvertida justificación de las limitaciones a la libertad de expresión. Para terminar, se procura detectar algunas pautas derivadas del Derecho Internacional y de la Constitución que son necesarias para las regulaciones de este tema.
\end{abstract}

Palabras clave: Discurso del odio, libertad de expresión y comunicación, democracia, protección de minorías.

Abstract: Starting from the three models of protection of the freedom of thought, an approach is made to the notion of "hate speech", detecting the challenges that exist to frame it, the risks and excesses presented by its regulation and going through the complex and controversial justification

1 Director de la Maestría en Derecho con énfasis en Derecho Constitucional y Derechos Humanos y profesor titular de Derecho Constitucional en pregrado y postgrado en la Universidad Católica del Uruguay. Correo electrónico: mrisso@ucu.edu.uy.

Recibido 5/5/2020. Aceptado 29/4/2020. Publicado 30/06/2020. 
of the limitations to the freedom of speech. Finally, it seeks to detect some guidelines derived from International Law and the Constitution that are necessary for «» the regulations of this subject.

Keywords: Hate speech, freedom of speech, democracy, minority protection.

\section{Introducción}

Pocos conceptos (o expresiones) resultan tan complejos en nuestros tiempos como el «discurso del odio». Es frecuente que se lo defienda con intensidad y sin mayor profundización, transformándolo en un objetivo básico, casi de principio, sin reparar en que está en tensión nada menos que con la libertad de expresión.

Un problema inicial que se presenta es que, como señala Brown², estas expresiones se relacionan con otras que se han usado históricamente para referirse a discursos que atacan a miembros o grupos de personas identificados con ciertas características: «odio racial», «libelo de grupo», "propaganda del odio o de la violencia», etc. Las confusiones iniciales son inevitables. Muchas veces, con las expresiones históricas, lo que se buscaba no era otra cosa que: a) silenciar opiniones consideradas peligrosas o que simplemente molestaban o incomodaban o generaban temor no fundado debidamente, como serían las que propugnan cambios sociales o económicos muy radicales, como fue el caso de Anita Whitney sobre el que volveré luego; o b) para silenciar las críticas y sancionar a los disidentes, como fue el caso de la Constitución soviética de 1936 que con la sanción de este tipo de discurso buscaba combatir toda forma de cuestionamiento. $^{3}$

Asimismo, la expresión más difundida de «discurso del odio» (hate speech) puede usarse al menos en tres sentidos: como simple referencia a un discurso, o comprendiendo la necesidad de combatirlo y evitarlo mediante la educación, la sanción ética y social, o como algo que debe ser

2 BRoWn (2017), p.427.

3 StRossen (2018), pp.24 y 25. 
sancionado penalmente, esto es, la criminalización del discurso del odio. Muchas veces no se sabe con precisión en qué sentido se está usando la expresión.

Podemos encontrar una acepción jurídica de «discurso del odio», pero frecuentemente se aprecia su uso no técnico, con contenido periodístico o político, sin presentar un grado razonable de precisión, sino más bien apuntando a algo amplio o especialmente vago.

La cuestión, a su vez, se ha politizado, y es frecuente encontrar la idea de que existe una cierta tendencia a favor de la criminalización del discurso del odio en ciertas posiciones que podrían calificarse de centro izquierda, mientras que las visiones de centro derecha suelen estar más preocupadas por la libertad de expresión. De todas formas, esto no debe verse como visiones opuestas, sino que se trata de enfoques que no siempre corresponden con el posicionamiento político o ideológico del sujeto. A veces, en el imaginario popular, se señalan estas tendencias políticas, aunque no sean tan claras ni demostrables en la realidad.

En su visión popular, en nuestros tiempos, parece que el «discurso del odio» es entendido como aquel que se asocia con el sujeto racista, homofóbico, islamofóbico, misógino, xenófobo, etc. Los valores invocados para el cuestionamiento de este discurso son claros: son los ideales de tolerancia, respeto y solidaridad, lo que da a esta posición un muy fuerte sustento ético. Estos se encuentran en aparente tensión con la libertad de expresión.

En algunos casos, se aprecia una fuerte imprecisión y hasta el vaciamiento del contenido de la noción. Al igual que ocurre con la expresión «fascista» que, de un contenido preciso en la primera mitad del siglo $\mathrm{XX}$, ha llegado a ser una expresión muy vaga que, para algunos, hoy no es más que un insulto casi vacío. En el mismo sentido, en muchas ocasiones el «discurso del odio» es usado solo como una forma de estigmatizar a quien, supuestamente, ha incurrido en esta práctica o como una justificación o excusa para limitar el ejercicio de la libertad de expresión. ${ }^{4}$

Estas concepciones, que surgen como reacción frente a una realidad

4 StRossen (2018), p.1. 
que desean modificar, en especial cuando se le dan fuertes sustentos morales, éticos y políticos, conducen frecuentemente a excesos inaceptables. Los defensores de la penalización del discurso del odio suelen disminuir el peso de estas extralimitaciones, planteándolas como malos desarrollos que no invalidan el instrumento en general. Unos invocan los daños que el discurso del odio causa en ciertos grupos y sus integrantes y otros apuntan a excesos inaceptables como los que se verán más adelante.

La idea de que es necesario combatir el discurso del odio es algo que avanza. No solo no hay un concepto claro, sino que es un concepto creciente que avanza incluso fuera del ámbito jurídico, por ejemplo, con el lenguaje del odio, que se eleva a una suerte de dogma inapelable: «inclusivos vs. no inclusivos». Y esto implica una estigmatización: los buenos, éticos y sensibles frente a los malos, no éticos e insensibles por el padecer de otros. Esto conduce frecuentemente al lenguaje de lo «políticamente correcto», que muchas veces no es más que un formalismo vacío. Cuando se plantean así las cosas es casi imposible tener un intercambio de ideas en serio.

También se advierten problemas a los efectos de determinar los límites del discurso del odio. Es muy claro que busca evitar la agresión basada en el racismo, religión, etc. ¿Pero hasta dónde se debe llegar? ¿Puede incluir la política $u$ otras formas de ataques o excesos verbales que pueden generar violencia? ¿Hasta dónde se llega y cuál es el fundamento para incluir ciertos casos sí y otros no?

La forma en que se encara el análisis del tema también es problemática. Los trabajos que comienzan hablando de la protección de ciertos grupos frente al discurso del odio tienden a admitir con facilidad restricciones en la libertad de expresión, mientras que los que comienzan preguntándose en qué casos es aceptable la restricción a la libertad de expresión, suelen llegar a soluciones distintas. La legislación contra el discurso puede implicar transitar por una pendiente resbaladiza: primero se combate el discurso del odio propiamente dicho, pero luego se amplía a otros casos, con la tentación inmensa de proscribir las opiniones que no se comparten, ofenden o se entienden peligrosas. 
Por último, aunque sin agotar el tema, debe señalarse que hay al menos tres visiones distintas de estas cuestiones: la europea, la estadounidense y la que corresponde a América Latina. La primera, ve como necesaria la limitación de la libertad de expresión con el propósito de combatir el discurso del odio. La segunda, si bien parte de premisas casi opuestas presenta distintas manifestaciones históricas y hoy tiene desarrollos especiales en los campus universitarios. La tercera, quizás, es la más equilibrada y protectora de la libertad de expresión, aunque con ciertos límites.

En un panorama tan complejo, se comenzará con la pregunta de cuál es la normativa internacional que se aplica y debe considerarse en el estudio de este tema y cuáles son las distintas perspectivas para el análisis de esta cuestión, buscando sus principales fundamentos y consecuencias.

A continuación, se analizará la justificación habitual para la criminalización del discurso del odio y los riesgos que implica.

Por último, y asumiendo que es necesaria una regulación mínima del discurso del odio, se intentará señalar cuáles son las pautas y criterios para esta regulación que derivan del Derecho Internacional y del Derecho Constitucional.

\section{2. ¿Cuál es la normativa aplicable al «discurso del odio»?}

\subsection{Normativa internacional}

El primer documento internacional claramente vinculado con esta problemática es la Convención para la Prevención y la Sanción del Delito de Genocidio ${ }^{5}$ (CPSDG), que dispuso en su artículo III que deben castigarse los actos de genocidio, la asociación para cometer genocidio, la instigación pública y directa para cometer genocidio, su tentativa y su complicidad. Y en el artículo IV se establece que quienes cometan genocidio o cualquiera de los otros actos enumerados en el artículo III, serán castigados, ya sean gobernantes, funcionarios o particulares.

5 Adoptada y abierta a la firma y ratificación, o adhesión, por la Asamblea General en su resolución 260 A (III), de 9 de diciembre de 1948. Entró en vigor: 12 de enero de 1951, de conformidad con el artículo XIII. 
"La Convención Internacional sobre la Eliminación de todas las Formas de Discriminación Racial (CIEDR), de 21 de diciembre de 1965, dispuso en su artículo 4:

Los Estados partes condenan toda la propaganda y todas las organizaciones que se inspiren en ideas o teorías basadas en la superioridad de una raza o de un grupo de personas de un determinado color u origen étnico, o que pretendan justificar o promover el odio racial y la discriminación racial, cualquiera que sea su forma, y se comprometen a tomar medidas inmediatas y positivas destinadas a eliminar toda incitación a tal discriminación o actos de tal discriminación, y, con ese fin, teniendo debidamente en cuenta los principios incorporados en la Declaración Universal de Derechos Humanos, así como los derechos expresamente enunciados en el artículo 5 de la presente Convención, tomarán, entre otras, las siguientes medidas:

a) Declararán acto punible conforme a la ley toda difusión de ideas basadas en la superioridad o en el odio racial, toda incitación a la discriminación racial, así como todo acto de violencia o toda incitación a cometer tales actos contra cualquier raza o grupo de personas de otro color u origen étnico, y toda asistencia a las actividades racistas, incluida su financiación;

b) Declararán ilegales y prohibirán las organizaciones, así como las actividades organizadas de propaganda y toda otra actividad de propaganda, que promuevan la discriminación racial e inciten a ella, y reconocerán que la participación en tales organizaciones o en tales actividades constituye un delito penado por la ley;

c) No permitirán que las autoridades ni las instituciones públicas nacionales o locales promuevan la discriminación racial o inciten a ella."

\section{El Pacto Internacional de Derechos Civiles y Políticos ${ }^{6}$ (PIDCP) dispone:}

"Artículo 19

1. Nadie podrá ser molestado a causa de sus opiniones.

2. Toda persona tiene derecho a la libertad de expresión; este derecho comprende la libertad de buscar, recibir y difundir informaciones e ideas de toda índole, sin consideración de fronteras, ya sea oralmente, por escrito o en forma impresa o artística, o por cualquier otro procedimiento de

6 Adoptado y abierto a la firma, ratificación y adhesión por la Asamblea General en su resolución $2200 \mathrm{~A}(\mathrm{XXI})$, de 16 de diciembre de 1966. Entró en vigor: 23 de marzo de 1976, de conformidad con el artículo 49. 
su elección.

3. El ejercicio del derecho previsto en el párrafo 2 de este artículo entraña deberes y responsabilidades especiales. Por consiguiente, puede estar sujeto a ciertas restricciones, que deberán, sin embargo, estar expresamente fijadas por la ley y ser necesarias para:

a) Asegurar el respeto a los derechos o a la reputación de los demás;

b) La protección de la seguridad nacional, el orden público o la salud o la moral públicas.

Artículo 20

1. Toda propaganda en favor de la guerra estará prohibida por la ley.

2. Toda apología del odio nacional, racial o religioso que constituya incitación a la discriminación, la hostilidad o la violencia estará prohibida por la ley."

Es sencillo advertir diferencias importantes en estos documentos. El primero, disponiendo que deberán ser castigados quienes cometan genocidio, o se asocien para cometerlo, instiguen directa y públicamente a cometerlo, sean cómplices o incurran en tentativa de genocidio, aparece como una norma razonablemente clara que no genera problemas.

Cuando se pasa a la CIEDR la cuestión no es tan clara. En efecto, el apartado «a» del artículo 4 condena y dispone que se adopten medidas conducentes a la eliminación de la incitación de la discriminación o actos de discriminación, pero penaliza la mera difusión, mientras que la primera parte es mucho más amplia. En efecto, se condena la propaganda y organizaciones que se inspiren en teorías o ideas basadas en la superioridad de una raza o grupo de personas, sin referencias a la incitación a la violencia y aun cuando no promuevan el odio y la discriminación. Se volverá sobre esto.

El Pacto de 1966, a continuación de la disposición que refiere a la libertad de expresión (artículo 19), excluye de esta la propaganda en favor de la guerra y toda apología del odio nacional, racial o religioso que constituya una incitación a la discriminación, la hostilidad o la violencia. El artículo 20 es sumamente preciso. El apartado 1 referido a la propaganda en favor de la guerra es muy claro y el apartado 2 con la referencia a la «apología» (esto es, defensa o alabanza) del odio nacional, racial o 
religioso y la exigencia de que dicha apología implique «incitación» a la discriminación, hostilidad o violencia, aparece como una norma precisa, equilibrada y compartible.

Este artículo 20 no prohíbe la mera apología, entendida como defensa, apoyo o promoción intencional del odio, sino que tal apología se convierte en delito cuando incita a la violencia, discriminación u hostilidad. Hay que incitar a actos de odio a una audiencia en particular y en un tiempo y lugar concretos ${ }^{7}$. Es una norma claramente adecuada y precisa, sin perjuicio de lo cual ha recibido críticas $^{8}$.

\subsection{Perspectiva estadounidense}

La Enmienda I de la Constitución de los Estados Unidos es muy clara y fija el punto de partida en esta materia:

"Congress shall make no law respecting an establishment of religion, or prohibiting the free exercise thereof; or abridging the freedom of speech, or of the press; or the right of the people to assemble, and to petition the Government for a redress of grievances."

Ante la imposibilidad de realizar un estudio detenido de la evolución estadounidense, y buscando mencionar los hitos más representativos, dos jueces de la primera mitad del siglo XX deben mencionarse. Oliver Wendell Holmes (miembro de la Corte Suprema entre 1902 y 1932) y Louis Brandeis (miembro de dicha Corte entre 1916 y 1936).

En 1919, en el caso Abrams v. United States ${ }^{9}$, luego de una interesante evolución personal ${ }^{10}$ y señalando que solo puede haber excepciones a la libertad de expresión en los casos de daño graves e inmediatamente próximos ${ }^{11}$, señaló Holmes:

"Pero cuando los hombres [...] [aceptan] que el bien último deseado se

7 RoLLNERT (2019), p.88. Se volverá sobre esto en la parte final.

8 HerRera (2014), p.81 refiere a la incidencia del Pacto en el artículo 10 del Convenio europeo y sus imprecisiones.

9 Corte Suprema (USA). Sentencia de 10 de noviembre de 1919.

10 Healy (2013).

11 SulLivan (2004), p.1016. 
alcanza mejor con el libre comercio de ideas, que la mejor prueba de la verdad es el poder del pensamiento para aceptarse a sí mismo en la competencia del mercado, y que la verdad es la única base sobre la cual sus deseos pueden llevarse a cabo de manera segura. Eso, en todo caso, es la teoría de nuestra Constitución. Es un experimento, como toda la vida es un experimento. Todos los años, si no todos los días, tenemos que apostar nuestra salvación a una profecía basada en el conocimiento imperfecto. Si bien ese experimento forma parte de nuestro sistema, creo que deberíamos estar eternamente vigilantes contra los intentos de limitar [check] la expresión de opiniones que detestamos y que creemos que están llenas de muertes, a menos que amenacen de manera tan inminente la interferencia inmediata con los propósitos legítimos y apremiantes de la ley que requiera un control inmediato para salvar el país".

En 1927, en Whitney v. California ${ }^{12}$, en su famosa discordia, el juez Brandeis, reflexionó respecto a la pregunta central para resolver el caso, esto es, si la conducta de la acusada constituye un claro y presente riesgo de daño sustancial (substantive evil). Recuerda que los hombres les temen a las brujas y por ello han quemado a muchas mujeres, y concluye que la libertad de expresión solo puede limitarse frente a peligros probados muy serios, graves e inminentes. Rechaza toda limitación basada en daños o riesgos simplemente probables. ${ }^{13}$

Algunos autores han señalado que el modelo estadounidense pone el foco en la protección del «disidente». Esto es, la tolerancia frente al intolerante, asumiendo como uno de los valores centrales la neutralidad del Estado ${ }^{14}$ frente a las distintas opciones religiosas, morales y políticas, independientemente del contenido del discurso ${ }^{15}$.

Por supuesto que también hubo excepciones a este modelo, por ejemplo, durante los tiempos del McCartyism en que los grupos minoritarios, que hoy claman por la limitación de la libertad de expresión para erradicar el discurso del odio, fueron los más beneficiados y enérgicos defensores

12 Corte Suprema (USA), sentencia de 6 de mayo de 1927.

13 Bhagwat (2004), p. 418 y 420.

14 Existen posiciones doctrinales más restrictivas de la libertad de expresión y que admiten una mayor injerencia, como es el caso de FISS (1986), pp. 153-158 y 518.

15 AlCÁCER (2015), p. 45 y 48. 
de la libre expresión ${ }^{16}$.

Un caso extremo encontramos en una sentencia de la Corte Suprema de 2011. La iglesia Baptista de Westboro, dirigida por el pastor Phelps, acoge como elemento central de su prédica el mensaje de que «Dios odia a los gais», y de que América ha sido maldecida por Dios por su decadencia moral al permitir la homosexualidad, especialmente dentro del ejército. El 10 de marzo de 2006 se celebró en Maryland el funeral del soldado Mathew A. Snyder, muerto en combate, al que acudieron a manifestarse los miembros de la iglesia mencionada, disponiendo sus pancartas en un terreno público a unos 300 metros de la iglesia donde tenía lugar el acto. El contenido de tales pancartas, recitado también de viva voz por los manifestantes, era del siguiente tenor: «Dios odia a EE. UU.», «América está maldita», «Tropas maricas», «Dios odia a los gais», «Los gais condenan a la nación».

La Corte, en Snyder v. Phelps17, del año 2011, amparó la libertad de expresión de Phelps y de los miembros de su iglesia señalando que dicha libertad puede ocasionar lágrimas, acciones o infligir grandes dosis de sufrimientos, pero debe protegerse el discurso, aunque cause mucho dolor.

Alcácer se pregunta: ¿Qué debe hacer un Estado democrático ante tales conductas? ¿Debe permitirlas, haciendo prevalecer la libertad de expresión frente a otros valores o sentimientos colectivos? ¿O debe prohibirlas, limitando así la libertad de expresión ante discursos hostiles, discriminatorios o vejatorios para un grupo? Dentro de esta última opción, ¿debe además sancionarlos penalmente? Si es así, ¿cuáles serían los bienes jurídicos protegidos? ¿Cuál sería el daño social que legitimaría acudir al Derecho Penal para castigar la manifestación de tales expresiones? Señala que Rawls, seguramente, hubiera preferido la libertad de expresión salvo casos excepcionales en que las instituciones democráticas no puedan operar efectivamente, y Dworkin, por su parte, ha reconocido el principio de que el discurso que odiamos requiere tanta protección

16 Chemerensky (2017), p. 40.

17 Citada por AlCÁCER (2015), p.45. 
como otro. ${ }^{18}$

De todas formas, debe señalarse en forma muy breve que en Estados Unidos y dentro de los campus universitarios se está verificando un proceso contrario a la visión anterior, en la medida que la mayoría de las universidades han venido aceptando limitaciones a la libertad de expresión con el propósito de excluir o limitar el discurso del odio en los campus.

\subsection{Perspectiva europea}

La visión europea es distinta a la anterior ${ }^{19}$ y es claro que la Segunda Guerra y el holocausto presentan una importancia básica. Así como la noción estadounidense de privacidad es esencialmente defensiva (el derecho a no sufrir intromisiones, el derecho a estar solo), la visión europea de privacidad refiere más al libre desarrollo de cada uno en la sociedad (vinculado a la dignidad de la persona humana), y así, respecto a la libertad de expresión, la perspectiva europea no se focaliza en el «disidente», sino en la "víctima» del discurso del odio. ${ }^{20}$

En materia de libertad de pensamiento suelen mencionarse como dos casos centrales en la jurisprudencia del Tribunal Europeo de Derechos Humanos, los casos Handyside (1976) ${ }^{21}$ y Sunday Times (1979) ${ }^{22}$, ambos contra el Reino Unido, en que se establecieron criterios precisos en cuanto a que la expresión "previstas en la ley» del artículo 10 del Convenio europeo requiere: a) que la ley sea suficientemente accesible, para que el ciudadano pueda disponer de informaciones que le permitan adecuarse a las circunstancias de las normas legales aplicables al caso; b) que la ley debe tener suficiente precisión que permita al ciudadano adecuar su conducta, pudiendo prever, con los asesoramientos correspondientes, las consecuencias que pueden tener sus actos; c) el Tribunal reconoce que no se puede exigir certeza absoluta pues la experiencia demuestra que está fuera de su alcance, aunque sería deseable, pero

18 AlCÁCER (2015), p.46.

19 АвA (2015), p.207.

20 AlCÁCER (2015), p.48.

21 TEDH sentencia 7 de diciembre de 1976.

22 TEDH sentencia de 26 de abril de 1979. 
reconoce que muchas leyes recurren a fórmulas vagas (Sunday Times, parágrafo 49).

También ha sostenido el TEDH que la injerencia en la libertad de expresión debe ser no solo necesaria, sino imperiosa (entendiendo por tal imprescindible) y no se puede justificar por razones de pertinencia, oportunidad o razonabilidad. Asimismo, debe recurrirse a la noción de proporcionalidad pues respecto a la injerencia en la libertad deben compensarse los sacrificios de quienes ejercen la libertad limitada y las ventajas de la sociedad en general ${ }^{23}$.

Debe recordarse además el «margen de apreciación nacional» que da a los Estados cierta libertad de acción en la restricción de los derechos. Esto se relaciona con los grados de uniformidad y consenso en cada caso: cuando mayor sea el grado de consenso menor será el margen de apreciación.

Pero en medio de dichos puntos de partida, la mayoría de los países europeos cuentan con una legislación fuerte de combate al discurso del odio y, en general, el Tribunal Europeo ha avanzado en esta línea.

Además de los mencionados instrumentos internacionales, en Europa aparecen normas, documentos y jurisprudencia que se orientan hacia el combate del discurso del odio. Por ejemplo, la Recomendación n. ${ }^{\circ} \mathrm{R}$ (97) 20, de 30 de octubre de 1997, del Comité de Ministros a los Estados miembros sobre discurso de odio, contiene en su apéndice una de las definiciones de discurso de odio más recurrentemente utilizadas: el término «discurso de odio» debe ser entendido abarcando toda forma de expresión que propague, incite, promueva o justifique el odio racial, la xenofobia, el antisemitismo u otras formas de odio basadas en la intolerancia, incluyendo la intolerancia expresada por el nacionalismo agresivo y etnocentrismo, la discriminación y la hostilidad contra las minorías, los inmigrantes y las personas de origen inmigrante. Sin duda esta Recomendación tiene un contenido más amplio e impreciso que el Pacto de $1966^{24}$. Repárese en la referencia a la mera propagación del odio, que

23 SERRANo (2011), p.583 y 584.

24 Ава (2015), p.208. 
tiene un carácter amplísimo. Asimismo, refiere a otras «formas de odio basadas en la intolerancia», lo que da pie para la inclusión de otros casos sin limitación alguna.

La Decisión Marco 2008/913/JAI del Consejo, de 28 de noviembre de 2008, que refiere a la aproximación de las disposiciones legales de los países miembros de la Unión, establece que determinadas manifestaciones graves del racismo y la xenofobia deben constituir un delito en todos los países de la UE y ser punibles mediante sanciones penales efectivas, proporcionadas y disuasorias. Se considerarán punibles como delitos penales determinados actos, tales como: incitación pública a la violencia o al odio, dirigidos contra un grupo de personas o contra un miembro de dicho grupo, en relación con la raza, el color, la religión o creencia, la ascendencia o el origen nacional o étnico; el delito anterior realizado con la difusión, por cualquier medio, de escritos, imágenes u otros soportes; apología pública, negación o trivialización flagrante de los crímenes de genocidio, crímenes contra la humanidad y crímenes de guerra tal como se define en el Estatuto de la Corte Penal Internacional, etc. Se agrega que, en cualquier caso, la motivación racista y xenófoba se considerará como una circunstancia agravante, o bien los tribunales deberán tener competencia para usar dicha motivación a la hora de determinar las sanciones aplicables.

Varios países miembros de la Unión tienen disposiciones constitucionales que refieren, directa o indirectamente, a este tema. La Constitución alemana, por ejemplo, en su artículo 18 prevé que quienes, para combatir el régimen fundamental de libertad y democracia, abusen de la libertad de expresión, de prensa, enseñanza, reunión, asociación, etc., pierden los referidos derechos.

Esta solución va en la misma línea que el artículo 17 de la Convención Europea de Derechos Humanos, utilizado por el TEDH para admitir la penalización del discurso del odio, que dispone:

"Prohibición del abuso de derecho. Ninguna de las disposiciones del presente Convenio podrá ser interpretada en el sentido de implicar para un Estado, grupo o individuo, un derecho cualquiera a dedicarse a una actividad o a realizar un acto tendente a la destrucción de los derechos o liber- 
tades reconocidos en el presente Convenio o a limitaciones más amplias de estos derechos o libertades que las previstas en el mismo."

En el caso Jersild c. Dinamarca ${ }^{25}$, señaló el TEDH que la exhibición de un programa de televisión en que se incluían expresiones de extremistas racistas no era discurso del odio, sino que se buscaba informar y contribuir al debate público. ${ }^{26}$ Pero en el caso Soulas c. Francia ${ }^{27}$, referido a un libro titulado "La colonización de Europa», si bien reconoció que había partes que eran de interés general, entendió el Tribunal que su contexto podía ocasionar una potencial reacción y constituir un peligro para la sociedad. Asimismo, consideró que en varios pasajes del libro había una visión negativa del islam. En mi opinión es un caso muy complejo pues parece que el Tribunal llegó demasiado lejos evaluando contenidos de un libro más allá de lo que debe ser un análisis jurídico.

Sin perjuicio de otros antecedentes, uno de los casos centrales en la jurisprudencia del TEDH es Féret $c$. Bélgica ${ }^{28}$, de 16 de julio de 2009. Daniel Féret era presidente de un partido político, diputado y responsable de escritos del partido publicados en la web de su propiedad. Hubo múltiples quejas respecto a que los escritos estaban inspirados en el racismo y la xenofobia. Los fueros de Féret fueron levantados y en definitiva fue acusado y condenado por un delito de opinión y luego esto fue confirmado en las instancias posteriores.

EI TEDH consideró que una condena penal implica una injerencia en la libertad de expresión, salvo si la limitación está prevista en una ley, persigue uno o más fines legítimos y es necesaria en una sociedad democrática para alcanzarlos. Para el TEDH la libertad de expresión es una de las bases de toda sociedad democrática y es necesaria en toda sociedad la defensa del libre juego del debate político. Pero también es base de una sociedad democrática la tolerancia y el respeto de la dignidad de todos los seres humanos. El Tribunal europeo dice que de la lec-

25 TEDH sentencia de 23 de setiembre de 1994.

26 PÉREZ (2009), p.18.

27 TEDH sentencia de 10 de octubre de 2008.

28 TEDH sentencia de 16 de julio de 2009. 
tura de las publicaciones de Féret se desprende fácilmente sentimientos de desprecio, rechazo y odio hacia los extranjeros y concluye que no se violó el artículo 10 del Convenio europeo con la sanción penal pues: a) es importante luchar contra la discriminación racial, b) la incitación al odio no requiere necesariamente el llamamiento a tal o cual acto de violencia o acto delictivo, c) bastaría con difamar o injuriar a ciertos grupos o con la incitación a la discriminación; y d) no importa la calidad de parlamentario de Féret, sino que justamente son los políticos quienes deben evitar este tipo de discursos.

En conclusión, «[e] I Tribunal examina los textos enjuiciados divulgados por el demandante y considera que las conclusiones de los tribunales internos sobre las publicaciones están plenamente justificadas. El lenguaje empleado por el demandante incitaba claramente a la discriminación y el odio racial, lo que no puede ser camuflado en el proceso electoral». En definitiva, considera justificada la condena de Féret y se aprecia que el discurso del odio debe ser penalizado aun dentro de un proceso electoral y cuando el sujeto tenga fueros parlamentarios.

Fuera de Europa se pueden encontrar legislaciones que criminalizan el delito del odio. Brown señala, por ejemplo, el caso de Sudáfrica, que considera delito la publicación, propagación, abrogación o comunicación de estos delitos, pero agrega que solo serán tales cuando claramente se aprecie la intención de ser hiriente, perjudicar o de incitar al daño o promover o propagar el odio ${ }^{29}$. Es claro que no basta con la propagación o comunicación, sino que la conducta delictiva debe asociarse a la intención de herir, perjudicar o incitar al daño.

Pero, en contra de lo anterior, en el año 2015, la Comisión Europea contra el Racismo y la Intolerancia (ECRI), declaró que las leyes contra el discurso del odio se han mostrado poco productivas y ha urgido a los Estados europeos a recurrir a otro tipo de herramientas para procurar su erradicación. La Unesco, por su parte, ha entendido que el contradiscurso es más efectivo que la supresión del discurso del odio para combatir

29 BRown (2017), p.435. 
a este último ${ }^{30}$. Barak Obama dijo en 2016, parafraseando a su abuela, que cuando un tonto habla solo está demostrando su propia ignorancia; déjalos hablar, pues si no lo haces, además, los victimizas. ${ }^{31}$

De todas formas, y fuera del discurso del odio, el TEDH ha tenido criterios muy protectores de la libertad de expresión. Por ejemplo, en el caso Arnaldo Otegui c. España ${ }^{32}$, referido a conceptos sobre el rol del rey de España a quien se lo consideró como el jefe de los que habían torturado personas en cierto operativo, sus autores fueron objeto de enjuiciamiento penal en España, pero el TEDH amparó la libertad de prensa, en decisión sumamente controvertida ${ }^{33}$, señalando que conforme el artículo 10 del Convenio solo puede limitarse la libertad de expresión en casos excepcionales cuando constituyan un discurso del odio o incitación a la violencia $^{34}$. Lo mismo respecto al caso José Gutiérrez c. España ${ }^{35}$, referido al rey de Marruecos.

\subsection{Perspectiva latinoamericana}

El artículo 13 de la Convención Americana, luego de reconocer el derecho de toda persona a la libertad de pensamiento y de expresión (que comprende la libertad de buscar, recibir y difundir informaciones e ideas de toda índole), que no puede admitirse la censura previa y solo responsabilidades ulteriores, dispone que estas responsabilidades deben ser para asegurar: el respeto a los derechos o a la reputación de los demás y la protección de la seguridad nacional, el orden público o la salud o la moral públicas. Más adelante se agrega la protección de la infancia y la adolescencia y se establece en el numeral 5:

"Estará prohibida por la ley toda propaganda en favor de la guerra y toda

30 STROSSEN (2018), p.23.

31 Citado por StRossen (2018), p.143.

32 TEDH sentencia de 15 de marzo de 2011.

33 SERRANo (2011), p. 585 y ss. En España el Tribunal Supremo había considerado que estas críticas al Jefe de Estado superaban la pauta de la necesariedad y eran más que declaraciones ignominiosas, hirientes o molestas (HERRERA (2014), p.86.

34 AlCÁCER (2018), p.4.

35 TEDH sentencia de 1 de junio de 2010. 
apología del odio nacional, racial o religioso que constituyan incitaciones a la violencia o cualquier otra acción ilegal similar contra cualquier persona o grupo de personas, por ningún motivo, inclusive los de raza, color, religión, idioma u origen nacional."

Nogueira, luego de señalar que desde el caso Handyside el parámetro de proporcionalidad es el adecuado para analizar la restricción normativa de los derechos fundamentales, repasa los subprincipios señalando respecto a la necesidad (o necesariedad) que debe distinguirse: i) una necesidad material, el medio debe ser el que afecte menos los derechos humanos; ii) la exigibilidad espacial, el medio debe ser aquel que establezca el menor ámbito de limitación de los derechos afectados; iii) la exigibilidad temporal, supone la delimitación más rigurosa del tiempo de aplicación de la medida que afecta derechos; y iv) la exigibilidad personal, debe limitarse en la medida de lo posible a las personas que sean afectadas en sus derechos. ${ }^{36}$

Este autor distingue tres etapas en la jurisprudencia de la Corte en materia de libertad de expresión. En la primera etapa de la Corte IDH, en la Opinión Consultiva $n^{\circ} 5$, usa el principio de proporcionalidad en la forma en que es desarrollado por la dogmática alemana. En la segunda etapa, ya en casos contenciosos, por ejemplo, en Olmedo Bustos y Otros vs. Chile ${ }^{37}$ (conocido como La última tentación de Cristo), la cuestión la resuelve la Corte no por ponderación, sino por subsunción, partiendo de la prohibición de censura previa, sin perjuicio de responsabilidades ulteriores.

En una tercera etapa, utiliza la ponderación y el principio de proporcionalidad para los casos de conflicto entre la libertad de expresión y el derecho a la honra (casos Kimel v. Argentina ${ }^{38}$ y Usón Ramírez v. Venezuela ${ }^{39}$ ) a través del criterio del peso de los bienes jurídicos, donde se destaca: a) el grado de afectación de uno de los bienes en juego, deter-

36 Nogueira (2011), pp.120 y 122.

37 Corte IDH sentencia de 5 de febrero de 2001.

38 Corte IDH sentencia de2 de mayo de 2008.

39 Corte IDH sentencia de 20 de noviembre de 2009. 
minando si la afectación fue grave, media o moderada; b) la importancia de la satisfacción del bien en contrario; y c) si la satisfacción de este justifica la restricción del otro. En Kimel se entendió que la afectación de la libre expresión del periodista e historiador fue grave, pero la afectación del derecho del exjuez fue mediana.

A su vez la Corte IDH ha dado distintas pautas para procesos electorales, cargos electivos y funcionarios en general:

a. El control democrático de la gestión pública, a través de la opinión pública, fomenta la transparencia de las actividades del Estado. En este sentido, en el caso Palamara Iribarne vs. Chile ${ }^{40}$, de 22 de noviembre de 2005 , se protegió a quien había sido procesado por declaraciones críticas respecto a integrantes de la jurisdicción militar. La Corte destacó la necesidad de apertura a un debate amplio sobre los funcionarios que es esencial para el funcionamiento de un sistema verdaderamente democrático (párrafo 83).

b. En Herrera Ulloa vs. Costa Rica ${ }^{41}$, sentencia de 2 de julio de 2004 , consideró que reproducir afirmaciones realizadas en la prensa europea y que comprometían la reputación de un funcionario destacado en Bélgica por la comisión de eventuales delitos, estaba protegido por la Convención.

c. En Ricardo Canese vs. Paraguay ${ }^{42}$, de 31 de agosto de 2004, respecto a la condena penal sufrida por afirmar que un candidato a la presidencia había sido «prestanombre» de la familia del antiguo dictador Alfredo Stroessner y que defendió sus intereses económicos, la Corte IDH consideró a la condena violatoria de la Convención.

d. En Kimel vs. Argentina ${ }^{43}$, de 2 de mayo de 2008, referido a un libro de Kimel que criticaba a un exjuez que a su juicio había sido condescendiente con la dictadura, la Corte entendió que el juez estaba

40 Corte IDH sentencia de 22 de noviembre de 2005.

41 Corte IDH sentencia de 2 de julio de 2004.

42 Corte IDH sentencia de 31 de agosto de 2004.

43 Corte IDH sentencia de2 de mayo de 2008. 
expuesto a un mayor escrutinio. El control democrático a través de la función pública fomenta la transparencia de las actividades estatales y promueve la responsabilidad de los funcionarios públicos.

e. El caso Tristán Donoso vs. Panamá, ${ }^{44}$ de 27 de enero de 2009, refiere a que el abogado Donoso había sido procesado por calumnia cuando afirmó que funcionarios habían interceptado irregularmente sus comunicaciones. La Corte consideró amparados por la Convención los dichos referidos. Protege el contexto en que se efectuaron las declaraciones.

f. En Usón Ramírez Vs. Venezuela ${ }^{45}$, de 20 de noviembre de 2009, se ampara la situación de un militar retirado que criticó fuertemente la actuación de las Fuerzas Armadas en el caso del "Fuerte Mara», y fue condenado por injurias con las Fuerzas Armadas.

Se aprecian criterios claros de máxima protección de la libertad de expresión en procesos electorales, así como un descenso importante en la protección de los candidatos a puestos electivos y quienes son electos para ellos. El umbral de protección baja considerablemente, aunque no desaparece.

También ha dicho la Corte que no está protegido por la Convención ${ }^{46}$ :

a. La propaganda de la guerra y la apología del odio que constituya incitación a la violencia (13.5). La Corte ha aceptado, siguiendo la jurisprudencia internacional, la imposición de sanciones por el abuso de la libertad de expresión bajo el cargo de incitación a la violencia, entendida como incitación a la comisión de crímenes, a la ruptura del orden público o de la seguridad nacional. Debe tenerse como presupuesto la prueba actual, cierta, objetiva y contundente de que la persona no estaba simplemente manifestando una opinión (por dura, injusta o perturbadora que sea), sino que tenía la clara intención de cometer un crimen y la posibilidad actual, real y efectiva de

44 Corte IDH sentencia de 27 de enero de 2009.

45 Corte IDH sentencia de 20 de noviembre de 2009.

46 Relatoría (2010), pp.20 y 21. 
lograr sus objetivos.

b. La incitación directa y pública al genocidio.

c. La pornografía infantil.

Ha señalado la Corte ${ }^{47}$ que se requiere compatibilidad con los principios democráticos y deben analizarse las legítimas necesidades de las sociedades democráticas y de las instituciones democráticas. Como reglas generales:

a. Las limitaciones deben estar establecidas por leyes redactadas de forma clara y precisa. La Corte exige que la ley penal tenga términos estrictos y unívocos que acoten claramente las conductas penales. En Usón Ramírez ${ }^{48}$, por ejemplo, dijo la Corte que no se cumplieron con estas exigencias del principio de legalidad.

b. Las limitaciones deben estar orientadas al logro de los objetivos imperiosos autorizados por la Convención. Estos fines son taxativos ${ }^{49}$.

c. Respecto al derecho de los demás debe realizarse una tarea de armonización, un balance. Es necesario que estos derechos se encuentren claramente lesionados o amenazados.

d. Las limitaciones deben ser necesarias en una sociedad democrática para el logro de los fines imperiosos que persiguen, estrictamente proporcionadas a la finalidad que buscan, e idóneas para lograr el objetivo imperioso que pretenden.

e. Las limitaciones no pueden implicar censura previa, sino solo deben referir a responsabilidades ulteriores.

f. Las limitaciones no pueden ser discriminatorias.

\subsection{Síntesis}

De lo anterior surge que los tres sistemas mencionados (europeo, estadounidense y Corte Idh) tienen, por un lado, algunos similares puntos

47 Relatoría (2010), pp.24 y 28.

48 Corte IDH sentencia de 20 de noviembre de 2009.

49 Caso Lagos del Campo v. Perú, de 31 de agosto de 2017. 
de partidas y criterios: características y trascendencia de la libertad de expresión, principio de legalidad (exigiendo leyes precisas y fácilmente comprensibles y accesibles); debe usarse el principio de proporcionalidad para el análisis de la regularidad jurídica de las responsabilidades ulteriores que se establezcan; no es admisible la censura previa; las limitaciones deben ser compatibles con el principio de libertad que constituye la solución de principio; deben perseguir fines imperiosos y compatibles con las necesidades de un sistema democrático, etc.

Pero, por otro lado, existe una tendencia mayor hacia la criminalización del discurso del odio en Europa (que no aparece como una posibilidad, sino como directiva a los Estados miembros de la Unión), así como una mayor amplitud a la hora de la criminalización ya que no siempre debe aparecer asociada a la apología de la discriminación, a la discriminación propiamente dicha o a la violencia u otras formas de actividades delictivas. El estudio de los distintos casos con las tres perspectivas enriquece mucho el análisis.

Asimismo, los énfasis en que el daño o peligro sea claro, totalmente probado (no meramente posible) y grave no necesariamente se aprecian en el modelo europeo.

Se trata de modelos que responden y se explican con base en distintas realidades y procesos históricos. En este sentido, y como se verá más adelante, los peligros de abusos y excesos de la criminalización del discurso del odio, si bien existen en Europa múltiples casos, son menos riesgosos que si se emplearan en otros continentes.

\section{La justificación de la criminalización del discurso del odio y sus riesgos}

Sin perder de vista la defensa de la libertad de expresión, parecería que, conforme las normas internacionales, habría una necesidad de establecer algún tipo de límite a los efectos de erradicar el discurso del odio (téngase presente el PIDCP). Pero la rápida referencia al derecho internacional y a los modelos mencionados pone de manifiesto que algunas normas que criminalizan el discurso del odio son demasiado amplias o 
vagas, mientras que otras presentan un grado de precisión razonable y pueden entenderse aceptables desde el punto de vista de la libertad de expresión. Asimismo, los criterios políticos y jurisprudenciales son variados y también aparecen algunos razonables y precisos y otros vagos y muy amplios. Y, en especial, no debe olvidarse que se está hablando de establecer responsabilidades ulteriores al ejercicio de uno de los derechos básicos para una sociedad democrática como lo es la libertad de expresión.

Dos preguntas aparecen ahora ¿cuáles son los riesgos de excesos que dicha regulación implica? y ¿cuál es la justificación de la regulación? Las dos preguntas están tan interrelacionadas que cualquiera podría ser el orden de análisis.

\section{1. ¿Cuáles son los riesgos que conlleva la regulación del discurso del odio?}

La criminalización del discurso del odio, al menos en sus orígenes, cuenta con una base ética muy sólida: la protección de ciertas minorías, el combate a la exclusión, la protección de quienes están sufriendo daños por pertenecer a un grupo determinado, etc. Pero fácilmente podemos encontrar múltiples excesos y un uso arbitrario de estas regulaciones. Es cierto que una lista de exageraciones no permite extraer conclusiones serias en cuanto a cuál es el riesgo de que estas regulaciones conduzcan a estas soluciones cuestionables, pero permite ver ciertos problemas que sí confirman lo sensible que es la libertad de expresión.

Strossen nos brinda un buen catálogo de excesos y todos ellos pueden haber sido muy bien intencionados ${ }^{50}$. Veamos algunos de ellos:

- Brigitte Bardot fue condenada en 2008 al pago de una multa por una carta dirigida al en ese entonces Ministro del Interior de Francia, Nicolás Sarkozy, en que se quejaba de los rituales que implicaban sacrificios de animales y decía que «los musulmanes están destruyendo el país imponiendo sus propias formas».

50 StRossen (2018), pp. 27-29 y 96. 
- Un niño inglés fue arrestado e investigado por exhibir en una demostración pacífica un cartel que decía «la siescentología no es una religión sino un culto peligroso».

- En 2016 un tribunal danés confirmó la condena de una persona que había publicado en Facebook que la ideología del islam abusa de la democracia para deshacerse de ella.

- En Francia se confirmó la condena de doce palestinos que ingresaron en un supermercado con un cartel que decía «larga vida a Palestina y boicot a Israel» y «comprando productos israelíes se legitiman los crímenes en Gaza».

- Un candidato inglés al parlamento europeo fue arrestado por un discurso, en el que, citando a Churchill, dijo que era inaceptable la idea de que la mujer pueda pertenecer a un hombre como ocurre con la ley islámica; mientras esto no cambie no desaparecerá la esclavitud.

Ben-Porath recuerda que, en 2015, las autoridades de la Universidad de Yale enviaron una comunicación a los estudiantes pidiendo que sean cautelosos y sensibles al elegir sus atuendos para Halloween. La profesora Erika Christakis respondió señalando que no podía haber tanta cautela y que las universidades debían tener espacio para que los estudiantes cometan errores, aunque puedan ser desagradables y un poco ofensivos. Los estudiantes se opusieron vehementemente y ejercieron presiones contra la profesora que terminó renunciando y también renunció su esposo. Luego, Christakis envió un mail al Washington Post señalando que las universidades deben ser espacios seguros para que los estudiantes maduren, aunque esto implica a veces prácticas regresivas o transgresoras, pero se han convertido más en un ambiente de censura y prohibiciones ${ }^{51}$.

Brown ${ }^{52}$ recuerda que en el Super Bowl de 2016, la artista Beyonce fue acompañada en su show por bailarines cuyos atuendos tenían algún

51 BEN (2017), pp.13-29.

52 BRown (2017), p.426. 
parecido con la forma de vestir de los Black Panther y se la criticó fuertemente por esto. En Uruguay, al poner en escena la obra Carmen, de Georges Bizet, se intentó modificar el final por ser en menoscabo de las mujeres.

¿Hasta dónde van a llegar estas limitaciones? ¿Cuál es el límite? Se empieza a no distinguir el arte del discurso intencionalmente de odio.

En cierta forma cada uno es hijo de su época. Chemerinzky señala que los actuales estudiantes universitarios estadounidenses, que han gozado desde hace décadas de una muy amplia libertad de expresión, están dispuestos a recortarla para el combate al discurso del odio lo que implica: por un lado, olvidar los tiempos (especialmente en los sesenta) en que otros universitarios protestaron fuertemente para que se les reconociera la libertad de expresión en los campus (por ejemplo, para protestar contra la guerra de Vietnam o la discriminación racial) y, por otra parte, fue la libertad de expresión la que sirvió y fue usada en el pasado por los grupos que ahora se intenta proteger mediante la limitación de esta libertad ${ }^{53}$.

Y no se olvide que además de los excesos, que hasta pueden ser bien intencionados, aparece o puede aparecer el manejo de esta herramienta por las autoridades como forma de silenciar el discurso molesto, crítico, desagradable o simplemente que cuestiona. Una vieja frase puede ser aplicable: si la única herramienta es un martillo pronto todo problema empieza a parecerse a un clavo.

Sin duda la regulación del discurso del odio, así como toda limitación de la libertad de la comunicación de pensamiento, implica ingresar en una pendiente resbaladiza en la que es muy difícil mantener el equilibrio. Más cuando el clamor popular es a favor de una causa noble: terminar con la exclusión, proteger a sujetos que están siendo dañados y discriminados, etc.

La vieja expresión de que «más vale un delincuente en la calle que un inocente en la cárcel», puede servir en este tema. Será que ¿es preferible que circule una idea u opinión que no debió circular a que una que sí

53 Chemerenzky (2017), p.12 y ss. y 74 y ss. 
debía hacerlo sea objeto de controles y se la excluya? No se olvide que la libertad de expresión es una de las bases del sistema democrático y una de las principales herramientas contra las violaciones de los derechos humanos.

\section{2. ¿Cuáles son las justificaciones para admitir este tipo de regulaciones?}

Mucho se ha dicho en esta materia. Los defensores a ultranza de la libertad de expresión y opositores a la regulación del discurso del odio señalan que: la sociedad no aceptará las limitaciones; el discurso del odio puede hasta ser útil pues permite ver opiniones que de lo contrario quedarían ocultas sin que hubiera consciencia de ellas; el combate del discurso del odio lleva a que las minorías sean visualizadas como víctimas y así sean vistos hasta por ellos mismos; la cura (limitación de la libertad de expresión) es peor que la enfermedad (discurso del odio) pues se sacrifica la primera sin atacar las causas profundas del problema ${ }^{54}$.

Los defensores de la regulación de la libertad de expresión invocan argumentos muy convincentes. Frecuentemente se señala que el discurso del odio lleva a la construcción de imágenes de las minorías en la opinión pública que pueden ser peligrosas (por ejemplo, las afirmaciones de algunos gobernantes en Estados Unidos de que todos los inmigrantes mexicanos y centroamericanos son delincuentes peligrosos son aceptadas sin cuestionamientos críticos por buena parte de la sociedad); que la regulación ayuda a abandonar malas prácticas y cambia la visión de los temas; que las víctimas del discurso del odio deben considerarse como víctimas como cualquier otra persona que haya sido objeto de un delito; etc.

Se invocan fuertemente contra la regulación los peligros de excesos y abusos en desmedro de la libertad de expresión y se citan los casos de Galileo, Locke, Voltaire, etc., pero se olvida que ninguno de ellos vivió bajo una democracia constitucional en que se tutelaran los derechos humanos. Se dice que estas regulaciones no implicaron problemas para la

54 Por ejemplo, Delgado (2018). 
libertad de expresión en Inglaterra o Suecia ${ }^{55}$.

Lo anterior es muy interesante. Cuando la policía persigue a un delincuente pueden producirse excesos de las autoridades que perjudiquen al presunto delincuente o a terceros, aunque nadie afirma que no debe perseguirse al delincuente, sino que hay que actuar en forma profesional, prudente, proporcional, etc. Con la libertad de expresión, la mera posibilidad de exceso es suficiente para que algunos rechacen toda regulación del discurso del odio. Aunque claro, la libertad de expresión, señalan sus defensores a ultranza, tiene una trascendencia especial.

La discusión es casi interminable y cada argumento, de uno y otro lado, puede ser rebatido.

El contradiscurso es señalado por muchos como la primera defensa contra el discurso del odio ${ }^{56}$, pero no hay evidencia que demuestre que sea mejor que la criminalización a la hora de combatirlo. Chemerinsky señala que se aprecia un cambio en las universidades estadounidenses en cuanto a que ahora los estudiantes esperan que sus puntos de vista no sean desafiados en los campus y en lugar de manifestar su desacuerdo con lo que se está diciendo en clase, optan por retirarse del salón ${ }^{57}$.

La libertad de expresión no es un derecho absoluto, sino que admite regulaciones y restricciones. Esto surge de las normas mencionadas anteriormente, pero también es claro que las restricciones deben presentar un sólido fundamento. No puede, por ejemplo, decirse simplemente que el discurso del odio no es ejercicio de la libertad de expresión, o como se dice en Estados Unidos que no se encuentra comprendido en la Enmienda I. Esto es una afirmación sin ningún sustento, algo que pretende justificarse por sí mismo. Cuando las normas protegen la libertad de expresión en «toda materia» o de «toda índole», no puede excluirse el discurso del odio de ella sin más; se requiere una mayor fundamentación.

Se ha señalado, y existe evidencia suficiente, que los daños que causa del discurso del odio pueden ser extraordinariamente graves, aunque

55 Delgado (2018).

56 StRossen (2018), p. 33.

57 CHEMERINZKY (2017), p.14. 
no necesariamente físicos. Llamar a alguien, especialmente si se trata de un niño, nigger, Paki, dirty jew, etc., en la mayoría de los casos es algo que supera ampliamente el insulto común. Este argumento conduce a ampliar la prohibición del discurso del odio a los casos en que se utilizan ciertas expresiones, aunque no haya habido intencionalidad o incluso daño.

El discurso del odio puede conducir a actos de violencia contra personas o contra la propiedad privada, pero claro, acá se está frente a un discurso que incita la violencia, la discriminación o genera hostilidad y, en estos casos, en general hay acuerdo en que debe haber sanción penal.

¿Se debe ser tolerante con el intolerante? Aquí aparece la problemática de qué tipo de Estado y de Constitución se tiene: ¿Una neutral o una militante? La primera, tiende a defender y tolerar la emisión de ideas incluso las que pueden ofender, molestar, dañar a otros sujetos o grupos minoritarios, mientras que la segunda protege a las víctimas del discurso del odio en ciertos casos tomando partido por grupos y opiniones determinadas.

Los argumentos a favor y en contra de las regulaciones presentan características comunes: a veces no son convincentes, o carecen de evidencia empírica, o no tienen la suficiente fuerza para derrotar a los que se esgrimen en contrario.

La mayoría de las discusiones, en especial en Estados Unidos, se plantean como una suerte de todo o nada, esto es, regulación del discurso del odio o libertad absoluta de expresión. Pero se debe rechazar esta disyuntiva total y ver la necesidad de buscar alternativas de armonización entre ambos extremos (libertad total o restricciones muy graves). La cuestión parece encontrarse más en la determinación de cuál es el marco en que se puede regular y con qué garantías.

Existe normativa internacional (convenciones y pactos internacionales) que orientan a los Estados en la línea de proteger a las víctimas del discurso del odio (esto no se puede negar) y existen situaciones que merecen la intervención estatal para la protección de ciertos grupos. Pero también existen disposiciones que protegen especialmente la libertad de expresión y que establecen cómo y en qué casos pueden establecerse 
restricciones.

La cuestión no es entonces «regulación del discurso del odio» frente a una «libertad total de expresión», sino que la cuestión se encuentra en partir de la libertad de expresión y ver en qué casos y con qué requisitos pueden establecerse restricciones (responsabilidades ulteriores) en esta materia, encontrando soluciones ajustadas a derecho y proporcionales ${ }^{58}$.

\section{Requisitos necesarios para aceptar la regulación penal del discurso del odio}

$\mathrm{Al}$ ingresar en este punto deben hacerse dos precisiones. La primera, es para aclarar que no se realizará ahora un análisis de tipo penal de este tema, sino solo se apuntará a las pautas que derivan, en forma explícita o implícita, de la normativa internacional y constitucional. Y la segunda, refiere a que se realizará una distinción entre los requisitos para la limitación de la libertad de expresión que podríamos llamar generales, de los particulares que interesan fundamentalmente en lo referido al combate al discurso del odio.

Los modelos mencionados antes tienen muchos puntos de coincidencias entre los tres o entre dos de ellos. Con carácter general se entiende que la libertad de expresión requiere, a los efectos de que sea aceptable su limitación, que:

- La restricción, que debe necesariamente establecerse por ley, sea clara y precisa y los ciudadanos deben poder acceder a ellas fácilmente y comprender con la mayor exactitud posible su contenido y cómo incidirá la regulación en sus discursos. Algunas leyes que tipificaban delitos han sido consideradas nulas por la falta de precisión en la descripción de la conducta tipificada como delito.

- La solución de principio es la libertad de expresión y sus excepciones requieren texto expreso y son de interpretación estricta.

- La intervención en la libertad de expresión debe responder a razo-

58 BEN (2017), p.27. 
nes imperiosas (esto es, imprescindibles y no meramente convenientes) orientadas al logro de los fines taxativos establecidos por el ordenamiento jurídico, que en el caso de la Convención Americana son la protección de los derechos y reputación de los demás, la seguridad nacional, el orden público, la salud o moralidad pública y, especialmente, la protección de niños y adolescentes.

- Las limitaciones deben ser necesarias para el desarrollo de una sociedad democrática, para el logro de los fines anteriormente establecidos.

- Las restricciones, salvo en el caso de los menores ${ }^{59}$, no pueden significar censura previa, sino responsabilidades ulteriores.

- Debe realizarse una tarea de armonización y ponderación de las restricciones, comparando los bienes jurídicos en pugna. Debe poder constatarse la idoneidad de la restricción para alcanzar el fin perseguido, la necesidad o necesariedad de la restricción (esto es, que no haya otra vía para alcanzar el objetivo perseguido que no lesione el derecho o lo lesione con menor intensidad) y, por último, debe realizarse una ponderación en sentido estricto.

Es muy claro que ciertos argumentos como que determinado discurso, por su contenido, no es «libertad de expresión», o que no se encuentra protegido por determinada norma no es suficiente. Lo mismo ocurre con la visión de que «no hay libertad para quienes son enemigos de la libertad». La libertad de expresión refiere a cualquier tema, toda materia, de toda índole y nada puede excluirse a priori, sin texto expreso. La exclusión o excepción debe basarse y cumplir con las pautas anteriormente mencionadas. De la misma forma, pretender que los intolerantes no deben ser tratados con tolerancia, no es más que algo contradictorio y sin fundamento.

Además de las condiciones generales ¿qué otros requisitos son imprescindibles para aceptar limitaciones a la libertad de expresión basa-

59 Muchas constituciones americanas no admiten siquiera la censura previa en este caso. Por ejemplo, artículo 29 de la Constitución uruguaya. 
das en el objetivo de combatir el discurso del odio?

Se ha señalado una cierta imprecisión en algunas normas internacionales y en el soft law. Si bien pueden señalarse dudas en cuanto a la precisión de algunas de estas disposiciones (me remito a lo dicho al analizar la Convención Internacional sobre la Eliminación de todas las Formas de Discriminación Racial), entiendo que los artículos 19 y, especialmente, el 20 del Pacto Internacional de Derechos Civiles y Políticos, cumple con los estándares de claridad al vincular la «apología» del odio nacional, racional o religioso, con la «incitación» a la discriminación, hostilidad o violencia.

Rollnert ve dificultades relevantes para definir los conceptos que describen la conducta sancionada. Señala, por ejemplo, que la versión del Pacto en inglés usa la expresión advocacy que no es sinónimo de «apología» y no significa tanto la justificación, el ensalzamiento, etc. Además, la vinculación de la apología con la incitación (a la discriminación, hostilidad y violencia), hace necesario que exista un riesgo inminente, esto es, los tribunales deberán evaluar si hubo posibilidades razonables de que la incitación tuviera éxito. ${ }^{60}$ En cierta forma, se advierte una proximidad con ciertos criterios estadounidenses ya mencionados, como el riesgo inminente, probado debidamente y muy grave.

Estas imprecisiones de las normas internacionales deben analizarse con cuidado y, a mi juicio, en la medida que estas regulaciones siempre implican limitaciones de la libertad de expresión, en caso de duda debe optarse siempre por la alternativa interpretativa que mejor se compadezca con la libertad de expresión.

Nos acercamos ahora a lo que algunos autores llaman el «triángulo del odio»: incitador, grupo víctima y terceros incitados. El contenido del discurso no es suficiente, sino que deben existir estas tres figuras.

Respecto al emisor, debe perseguir, intencionalmente, la referida incitación. Una obra artística que no tiene esa motivación no puede quedar comprendida en la figura prohibida y lo mismo ocurre con expresiones científicas, referencias históricas, etc. Puede verse que muchos de

60 RolLneRT (2019), pp.85 y 88. 
los casos sintetizados para demostrar algunos excesos en la aplicación de estos instrumentos no parece que puedan ser aceptados con estos criterios.

Asimismo, la incitación (sin la cual no habría infracción) debe ser a la discriminación, a la hostilidad y a la violencia, conforme el Pacto Internacional de Derechos Civiles y Políticos. No pueden agregarse otros objetivos. La incitación debe situarse entonces espacial y temporalmente a los efectos de poder determinar si la incitación tuvo éxito o si pudo haberlo tenido. Si se trató de una expresión vacía o aislada, sin ninguna posibilidad de éxito, no estaremos dentro del discurso del odio criminalizable.

Lo mismo ocurre con el tercer vértice del triángulo, la existencia del público o grupo incitado, que es imprescindible según se desprende del artículo 20 del Pacto. Esto significa la necesidad de poder individualizar, al menos en forma general, a este grupo, situado espacial y temporalmente. El contexto es claro ya que según sus características dependerá la magnitud del daño y la inminencia del efecto de la incitación. Aparece acá el problema de la idoneidad, capacidad o posibilidad de incitar, efectivamente, a la violencia, discriminación u hostilidad. Basta con que la posibilidad exista, sin perjuicio de que haya tenido éxito. Acá también juega la noción de peligro serio (no menor) e inminente (no alcanza con la mera probabilidad), lo que se aproxima a la jurisprudencia estadounidense de la primera mitad del siglo XX citada.

El grupo víctima, originalmente, era muy sencillo: grupos nacionales, religiosos y raciales, como surge del propio artículo 20. Pero se advierte una tendencia a ampliarlos, penalizando discursos homofóbicos, contra la mujer, etc.

Pero además estos grupos tienen que sufrir un daño grave ${ }^{61}$, debe tratarse de una intención de dañar, de perjudicar, de herir. Este último extremo no surge en forma clara del Pacto y deberá analizarse con cuidado con una perspectiva penal. Un comentario menor, que no causa un agravio serio (y que seguramente sus posibilidades de incitar son muy limitadas) ¿puede configurar un delito de odio? Esto no debe llamar la

61 Delgado (2018). 
atención. Frente a un comentario como "a esta persona la mataría» ¿se puede considerar esto por sí mismo una amenaza? Sin duda depende del caso y del contexto. Dejo la cuestión planteada para los abordajes del tema con una perspectiva penal.

Un problema que genera infinitos problemas puede resumirse diciendo ¿la mera justificación del odio o de la violencia puede constituir delitos de odio ${ }^{62}$ Si fuera así ¿qué debería hacerse con la conmemoración de batallas históricas que enfrentaron a dos naciones? Definitivamente no se está en este caso frente a un discurso del odio, ya que cuando se conmemora algún aspecto o hecho referido a la independencia de América, por ejemplo, no hay ni intención de dañar ni incitación al odio contra las viejas potencias coloniales.

Un caso especial aparece con el «negacionismo», entendiendo por tal la negación de la existencia del holocausto del pueblo judío durante la Segunda Guerra Mundial o su reducción a una mínima expresión. Los hechos históricos por definición son opinables y revisables, pero son varios los países europeos que han criminalizado el negacionismo. Algunos autores, ante este problema, distinguen claramente la negación del holocausto de otras formas de «negacionismo», con lo que acotan la cuestión al holocausto ${ }^{63}$ y lo limitan a lo que algunos califican como reempaquetado del nazismo (se lo llama por otro nombre y, además, se victimizan a los responsables de los hechos).

Rollnert ${ }^{64}$ se pregunta si el negacionismo es un peligro para la democracia. Contesta negativamente y cuestiona el uso del abuso de derecho del art. 17 de la Convención y su interpretación expansiva a la que se hizo mención cuando se analizó el modelo europeo. Pero no es una respuesta unánime pues otros consideran que negar o socavar el holocausto significa afectar las bases del sistema democrático europeo y la defensa contra el autoritarismo (sería una afectación simbólica al espíritu

62 RolLnert (2019), p.92.

63 HeINZE (2016), p.23.

64 RolLnert (2019), pp.102 y ss. 
democrático europeo $)^{65}$.

Parece claro que la negación de algo tan evidente como el holocausto debe perseguir algún fin espurio, pero hay otras cuestiones también evidentes cuya justificación o negación no genera respuestas penales. Aparece entonces la pregunta central: ¿no será lo mejor defenderse con el contradiscurso y evitar, todavía, la victimización de los responsables? Posiblemente la perspectiva europea y su propia historia conduzcan a la aceptación del negacionismo como delito, pero en los otros modelos parece más prudente y efectivo que semejantes afirmaciones ingresen en el mercado de ideas y sean rebatidas por los opositores a ellas para lo que sobrarán argumentos.

Este es uno de los aspectos más discutibles del combate al discurso del odio. Es complejo restringir opiniones sobre hechos históricos, cualesquiera que ellas sean y, más difícil es defender por qué la restricción es respecto a ciertos hechos abominables, pero no frente a otros. La discusión no parece tener un fin próximo.

Por razones de espacio no ingresaré en el estudio del combate al discurso del odio en los campus universitarios de los Estados Unidos (esto justificaría un análisis específico), pero sí resulta a mi juicio preocupante que se admita tan ligeramente la restricción de la libertad de expresión en lugares en los que dicha libertad es una de las bases principales: todos los puntos de vista deben poder ser expresados en un campus sin importar que sean molestos, incómodos u ofensivos para algunos.

Chemerinsky plantea dos principios básicos (válidos incluso fuera de los campus): a) el campus no puede censurar o penalizar un discurso simplemente porque una persona o grupo lo considera ofensivo u odioso; y b) solo puede el campus sancionar el discurso que cumpla con criterios legales y que impliquen acoso, amenazas verdaderas y serias ${ }^{66}, 0$ que sea orientado a la destrucción de bienes, interrupción de la actividad universitaria, etc. ${ }^{67}$. En general, las restricciones que se advierten en los

65 AlCÁCER (2013), pp.336 y 340.

66 CHEMERENZKY (2017), pp.112 y 113.

67 Chemerenzky (2017), pp. 115 y ss. 
campus exceden claramente estas pautas e implican un retroceso en el ambiente de libertad que debe regir en las universidades.

\section{Conclusión}

La regulación del odio tiene problemas iniciales importantes. Por un lado, implica limitaciones a la libertad de expresión de pensamiento, lo que siempre es riesgoso y debe procurar evitarse. Por otra parte, la protección de ciertos grupos minoritarios objeto de agresiones, discriminación, hostilidad o violencia, con consecuencias graves, es necesaria y debe ser efectiva. Menuda disyuntiva.

No cabe duda de que el discurso del odio debe combatirse con la educación, con sanciones éticas, políticas, sociales, etc. Es más, seguramente estas son las alternativas más efectivas a largo plazo. Pero en lo inmediato, mientras las otras alternativas aún no dan sus frutos, debe recurrirse a sanciones penales y, como responsabilidades ulteriores al discurso, condenar a los autores.

A esta altura no parece que pueda existir una oposición absoluta a la penalización del discurso del odio, pero sí es muy claro que la tipificación legal debe ser sumamente clara, precisa y acotada.

Como ya se señaló todas las garantías para la limitación de un derecho humano y las especiales para la libertad de expresión son válidas y deben ser tenidas en cuenta. A saber: las restricciones requieren ley, clara, precisa y de fácil comprensión para quien emitirá una opinión, que debe poder saber cuáles serán las consecuencias de su discurso. Las responsabilidades ulteriores solo pueden perseguir los objetivos del artículo 13 de la Convención Americana, los que aparecen como fines taxativos, de excepción y de interpretación estricta. Las limitaciones deben ser también compatibles con las necesidades imperiosas de una sociedad democrática y deben poder sortear un juicio de proporcionalidad: idoneidad, necesidad y ponderación en sentido estricto.

En lo que concretamente refiere al discurso del odio debe tenerse presente el referido triángulo del odio: a) el emisor que debe, intencionalmente, intentar causar o causar un daño grave a ciertos sujetos o grupos, 
procurando la incitación a la violencia, la discriminación o la hostilidad contra cierto grupo; b) las víctimas deben pertenecer a grupos raciales, religiosos o nacionales (sin perjuicio de recordar la peligrosa tendencia a ampliar estos grupos) y deben sufrir o tener un riesgo acreditado de sufrir un daño claro y de gran intensidad (no es suficiente la molestia o la ofensa frente al uso de una expresión); y c) el tercer vértice del triángulo, grupo incitado, es básico y debe definirse con cierta precisión y situarlo temporal y espacialmente para poder analizar si el riesgo de incitación a la violencia, discriminación y hostilidad realmente existió (la incitación debe ser efectiva, esto es generar los efectos perseguidos, o debe existir una posibilidad de riesgo cierta y grave, que vaya más allá de meras conjeturas). Y no debe olvidarse el contexto, pues no es lo mismo pintar una esvástica frente a una sinagoga o frente a una escuela de niños judíos que en otro lugar en general no visible para el público.

La elaboración de normas penales que cumplan con las bases anteriores no es tarea sencilla, pero esto ya forma parte de las políticas y técnicas legislativas y del asesoramiento de especialistas en Derecho Penal.

Y siempre debe tenerse presente que cuando se limita la libertad de expresión se está haciendo algo inusualmente grave y, en caso de duda, debe preferirse la libertad por sobre la limitación.

\section{Bibliografía}

Aba CatolRa, Ana (2015): "Protección de las libertades de expresión y sanción del discurso del odio en las democracias occidentales", en Anuario de Facultade de Dereito da Universidade da Coruña,(19), Coruña, pp. 199-222. Fecha de consulta: 12 setiembre de 2018. Disponible en https://ruc.udc.es/dspace/bitstream/handle/2183/16829/ AD_2015_19_art_10.pdf?sequence=1\&isAllowed=y

AlCÁCER GuiraO, Rafael (2013): "La libertad de expresión, negación del holocausto y defensa de la democracia”, en Revista Española de Derecho Constitucional, Madrid, (No 97, enero - abril 2013), pp. 309-341. AlcÁcer Guirao, Rafael (2015): "Víctimas y disidentes. El "discurso del odio" en EEUU y Europa”, en Revista Española de Derecho Constitu- 
cional, Madrid, (№ 103, enero - abril 2015), pp. 45-86.

AlcÁcer Guirao, Rafael (2018): "Opiniones constitucionales”, en Revista para el Análisis de Derecho, InDret, Facultad de Derecho de Murcia, Barcelona, (enero de 2018), pp. 1 - 38. Fecha de consulta: 14 febrero de 2019. Disponible en https://www.indret.com.

Ben-Porath, Sigal R. (2017): Free speech on campus, (University of Pennsylvania Press, versión Kindle, Philadelphia, Pennsylvania).

Bhagwat A. Ashutosh (2004): "The story of Withney v. California: the power of ideas", en Constitutional law stories, (edit. Foundation Press, New York, Thomson West).

Brown, Alexander (2017): "What is hate speech? Part I: The myth of hate speech", en Law and Philosophy, $(2017,36)$, pp. 419-468. Fecha de consulta 4 de junio de 2018. Disponible en https://link.springer.com/ content/pdf/10.1007\%2Fs10982-017-9297-1.pdf

Chemerinsky, Erwin y Gillman, Howard (2017): Free speech on campus,( Yale, University Press, New Haven and London, versión Kindle).

Delgado, Richard y Stefancic, Jean (2018): Must we defend nazis? Why the First Amendment should not protect hate speech and white supremacy? (New York University Press, New York, EEUU, versión Kindle). FISs, Owen M. (1996): The irony of free speech, (Harvard University Press, Cambridge, Massachusetts, USA).

Healy, Thomas (2013): The great dissent. How Oliver Wendell Holmes change his mind and change the history of free speech in America,( Metropolitan Books Henry Holt and Company, New York, New York). HeInZE, Eric (2016): Hate speech and democratic citizenship, (Oxford University Press, Oxford, versión Kindle).

Herrera, David Martín (2014): “¿Cuándo el hate speech se convierte en hate crime? Libertad de expresión y Derecho Internacional según el TEDH", en Revista de la Facultad de Derecho de la Universidad Nacional de Córdoba, vol. V, № 2, nueva serie II, pp. 73 - 96, Córdoba. Fecha de consulta 4 de noviembre de 2018. Disponible en https://revistas.unc.edu.ar/index.php/refade/article/view/11547

Nogueira Alcalá, Humberto (2011): "El uso del postulado de proporcionalidad en la jurisprudencia de la Corte Interamericana de Derechos 
Humanos sobre libertad de expresión", en Estudios Constitucionales, Año 9, № 1, Talca, Chile, pp. $119-156$.

Pérez-MAdRID, Francisca (2009): "Incitación al odio religioso o hate seech y libertad de expresión", en Revista General de Derecho Canónico y Derecho Eclesiástico del Estado, 19, Barcelona, pp. 1-28.

Relatoría Especial para la Libertad de Expresión y Comisión Interamericana de Derechos Humanos, 2010, Marco Jurídico interamericano sobre el derecho a la libertad de expresión. Fecha de consulta 4 de noviembre de 2018. Disponible en http://oas.org/es/cidh/expresion/docs/ publicaciones/MARCO\%20JURIDICO\%20INTERAMERICANO\%20 DEL\%20DERECHO\%20A\%20LA\%20LIBERTAD\%20DE\%20EXPRESION\%20ESP\%20FINAL\%20portada.doc.pdf

RolLnERT LieRN, Göran (2019): "El discurso del odio: una lectura crítica de la regulación internacional", en Revista Española de Derecho Constitucional, 115, 81 - 109, Madrid.

SerRano Mállo, Isabel (2011): "El derecho a la libertad de expresión en la jurisprudencia del Tribunal Europeo de Derechos Humanos: dos casos españoles", en UNED, Teoría y Realidad Constitucional, $n^{\circ} 28$, pp. 579-596, España. Fecha de consulta 2 de diciembre de 2018. Disponible en Biblioteca Jurídica Virtual del Instituto de Investigaciones Jurídicas de la UNAM, http://biblio.juridicas.unam.mx

Strossen, Nadine (2018): Why we should resist it with free speech, not censorship, Inalienable Rights series, (edit. Oxford University Press, New York, edición Kindle).

Sullivan, Kathleen M. y GunTher, Gerald (2004): Constitutional Law (New York, Foundation Press, New York, New York, Thomson West).

Teruel Lozano, Germán M. (2015): "La libertad de expresión frente a los delitos de negacionismo y de provocación al odio y a la violencia: sombras sin luces en la reforma del código penal", en Revista para el Análisis de Derecho, InDret, Facultad de Derecho de Murcia, Barcelona, octubre de 2015, pp. 1 - 51. Fecha de consulta 6 de diciembre de 2018. Disponible en https://www.academia.edu/17424419/ 


\section{Jurisprudencia citada}

Lagos del Campo vs. Perú, (2017), Corte IDH, sentencia de 31 de agosto de 2017 (libertad de expresión). Fecha de consulta 4 de setiembre de 2019. Disponible en http://www.corteidh.or.cr/

Arnaldo Otegi Mondragón c. España, (2011), TEDH sentencia de 15 de marzo de 2011 (libertad de expresión). Fecha de consulta 4 de abril de 2019. Disponible en http://hudoc.echr.coe.int

José Gutiérrez c. España, (2010), TEHD sentencia de 1 de junio de 2010 (libertad de expresión). Fecha de consulta 2 de abril de 2019. Disponible en http://hudoc.echr.coe.int.

Féret c. Bélgica, (2009), TEDH sentencia de 16 de julio de 2009 (libertad de expresión, discurso del odio y derechos políticos). Fecha de consulta 2 de abril de 2019. Disponible en http://hudoc.echr.coe.int

Usón Ramírez vs. Venezuela, (2009), Corte IDH, sentencia de 20 de noviembre de 2009 (libertad de expresión y personas públicas). Fecha de consulta 4 de setiembre de 2018. Disponible en http://www. corteidh.or.cr/

Tristán Donoso vs. Panamá, (2009) Corte IDH sentencia de 27 de enero de 2009 (libertad de expresión). Fecha de consulta 10 de setiembre de 2018. Disponible en http://www.corteidh.or.cr/

Soulas c. Francia, (2008), TEDH sentencia de 10 de octubre de 2008 (libertad de expresión). Fecha de consulta 4 de abril de 2019. Disponible en http://hudoc.echr.coe.int

Kimel vs. Argentina, (2008), Corte IDH, sentencia de 2 de mayo de 2008 (libertad de expresión y personas públicas). Fecha de consulta 8 de setiembre de 2018. Disponible en http://www.corteidh.or.cr/

Palamara Iribarne vs. Chile, (2005), Corte IDH sentencia de 22 de noviembre de 2005 (libertad de expresión). Fecha de consulta 4 de setiembre de 2018. Disponible en http://www.corteidh.or.cr/

Ricardo Canese vs. Paraguay, (2004), Corte IDH sentencia de 31 de agosto de 2004 (libertad de expresión). Fecha de consulta 11 de setiembre de 2018. Disponible en http://www.corteidh.or.cr/

Herrera Ulloa vs. Costa Rica, (2004), Corte IDH sentencia de 2 de julio 
de 2004 (libertad de expresión). Fecha de consulta 4 de setiembre de 2018. Disponible en http://www.corteidh.or.cr/

Olmedo Bustos y Otros vs. Chile, (2001), Corte IDH sentencia de 5 de febrero de 2001 (exhibición de película y prohibición de censura previa). Fecha de consulta 4 de setiembre de 2018. Disponible en http://www. corteidh.or.cr/

Jersild c. Dinamarca, (1994), TEDH sentencia de 23 de setiembre de 1994 (libertad de expresión). Fecha de consulta 4 de abril de 2019. Disponible en http://hudoc.echr.coe.int

La colegiación obligatoria de los periodistas de Costa Rica, (1985), Corte IDH Opinión Consultiva N 5/85, de 13 de noviembre de 1985. Disponible en http://www.corteidh.or.cr/

Sunday Times contra Reino Unido, (1979), TEDH sentencia de 26 de abril de 1979 (libertad de expresión). Fecha de consulta 4 de abril de 2019. Disponible en http://hudoc.echr.coe.int

Handyside contra Reino Unido, (1976), TEDH sentencia de 7 de diciembre de 1976 (libertad de expresión). Consultado 4 de abril de 2019. Disponible en http://hudoc.echr.coe.int

Whitney v. California, (1927) Corte Suprema de Justicia (USA) sentencia de 6 de mayo de 1927 (libertad de expresión y sus límites). Consultado 4 de marzo de 2018. Disponible en https://www.law.cornell.edu/ supremecourt/text/274/357

Abrams v. United States, (1919) Corte Suprema de Justicia (USA), 10 de noviembre de 1919 (libertad de expresión y sus límites). Consultado 4 de marzo de 2018. Disponible en https://link.springer.com/content/ pdf/10.1007\%2Fs10982-017-9297-1.pdf 
